\title{
Implications of the Recent Reductions in Natural Gas Prices for Emissions of \(CO_2V from the US Power Sector
}

\section{Citation}

Lu, Xi, Jackson Salovaara, and Michael B. McElroy. 2012. Implications of the recent reductions in natural gas prices for emissions of $\backslash\left(C O \_2\right)$ from the US power sector. Environmental Science \& Technology 46(5): 3014-3021.

\section{Published Version}

doi:10.1021/es203750k

\section{Permanent link}

http://nrs.harvard.edu/urn-3:HUL.InstRepos:10029444

\section{Terms of Use}

This article was downloaded from Harvard University's DASH repository, and is made available under the terms and conditions applicable to Open Access Policy Articles, as set forth at http:// nrs.harvard.edu/urn-3:HUL.InstRepos:dash.current.terms-of-use\#OAP

\section{Share Your Story}

The Harvard community has made this article openly available.

Please share how this access benefits you. Submit a story.

\section{Accessibility}




\title{
Implications of the Recent Reductions in Natural Gas Prices for Emissions of $\mathrm{CO}_{2}$ from the US Power Sector
}

\author{
Xi Lu \\ School of Engineering and Applied Sciences, Harvard University, Cambridge, MA 02138, USA \\ Address: Cruft Lab 211a, 19 Oxford St., MA 02138 \\ Email: xilu@fas.harvard.edu \\ Phone: 617-496-6365
}

Jackson Salovaara

School of Engineering and Applied Sciences, Harvard University, Cambridge, MA 02138, USA

Address: Cruft Lab 211, 19 Oxford St., MA 02138

Email: jackson.salovaara@gmail.com

Michael B. McElroy*

School of Engineering and Applied Sciences and Department of Earth and Planetary Sciences, Harvard University, Cambridge, MA 02138, USA

Address: 100G Peirce Hall, 29 Oxford St., MA 02138

Email: $\underline{\text { mbm@seas.harvard.edu }}$

Phone: (617) 495-4359

Corresponding Author:

Michael B. McElroy (mbm@seas.harvard.edu) 


\section{Abstract}

$\mathrm{CO}_{2}$ emissions from the US power sector decreased by $8.76 \%$ in 2009 relative to 2008 contributing to a decrease over this period of $6.59 \%$ in overall US emissions of greenhouse gases. An econometric model, tuned to data reported for regional generation of US electricity, is used to diagnose factors responsible for the 2009 decrease. More than half of the reduction is attributed to a shift from generation of power using coal to gas driven by recent decrease in gas prices in response to the increase in production from shale. An important result of the model is that when the cost differential for generation using gas rather than coal falls below 2-3 cents/kWh, less efficient coal fired plants are displaced by more efficient natural-gas-combined-cycle (NGCC) generation alternatives. Costs for generation using NGCC decreased by close to 4 cents/kWh in 2009 relative to 2008 ensuring that generation of electricity using gas was competitive with coal in 2009 in contrast to the situation in 2008 when gas prices were much higher. A modest price on carbon could contribute to additional switching from coal to gas with further savings in $\mathrm{CO}_{2}$ emissions.

\section{Introduction}

US emissions of greenhouse gases decreased by $2.94 \%$ in 2008 relative to 2007 and by a further $6.59 \%$ in 2009 (1). Emissions from the power sector, which accounts for approximately $40 \%$ of total US greenhouse gas emissions (1), declined by an even larger factor, by $8.76 \%$ in 2009 relative to 2008 . The overall decrease in emissions may be attributed to the recession 
in the economy that set in during late 2008. A contributing factor for the power sector, however, relates to an important shift from coal to natural gas that took place over this period in generation of electricity in the US. Total production of electricity declined by $4.1 \%$ in 2009 relative to 2008 . Over the same interval, production from coal decreased by $11.63 \%$ while the contribution from natural gas combined cycle (NGCC) plants rose by $7.18 \%$ (2).

The shift from coal to gas was triggered to a large extent by a significant decrease in the cost of natural gas relative to coal. Prices for natural gas consumed in the power sector fell from a high of $\$ 12.06 / \mathrm{MMBTU}\left(1 \mathrm{MMBTU}=10^{6} \mathrm{BTU}\right)$ in June 2008 to a low of $\$ 3.97 /$ MMBTU in September 2009. Prices have fluctuated since around an average of about $\$ 5 /$ MMBTU (3-4). The recent persistent decrease in gas prices is attributed primarily to an increase in the production of gas from shale facilitated by developments in horizontal drilling and by technological advances involving injection of high pressure water and chemicals into gasrich shales, the process referred to as fracking. The price of coal has been relatively stable, increasing modestly, over this period.

A diversity of sources contributed to the generation of electricity in the US in 2010: coal accounted for approximately $56.1 \%$ of the total followed by nuclear $(17.3 \%)$, natural gas (15.5\%), hydro (9.5\%) and wind (2.3\%) (5). Utilities have an incentive to produce electricity at the lowest possible cost to meet demand subject to constraints imposed by transmission limitations and by requirements for ancillary services including the regulation of reactive power, voltage and frequency (6-7). Decisions as to which plants are deployed by a utility at any given time depend on consideration of a combination of operational and maintenance costs 
(O\&M), fuel prices, and the efficiency with which plants can convert specific sources of energy to electricity $(6,8)$. In practice, wind, hydro, nuclear and solar facilities, for which immediate power generation costs are typically low, rate highest on what is referred to as the economic merit order: these sources are deployed first to meet demand (8) and will generate as much electricity as they can subject to existing capacities. Their deployment is relatively insensitive in the short term to variations in prices for coal and natural gas (2). When prices for gas are high relative to coal, coal resources are deployed typically to meet baseload demand with gas plants operated primarily to accommodate occasions where demand for electricity is particularly high. If prices for gas are low relative to coal, the most efficient gas plants may be engaged to displace the least efficient coal plants in the economic merit order (9).

The price induced transition from coal to gas in the power sector offers an important opportunity to diagnose the response of the US power sector to a changing differential price for coal relative to gas. The primary objective of the present study is to quantify the role low gas prices played in the recent reduction in emissions of $\mathrm{CO}_{2}$ from the US power sector. A secondary objective is to identify additional reductions that could be achieved through the introduction of a carbon tax, a levy specifically targeting emissions from the power sector. A number of previous studies have investigated the short-term impact of a hypothetical tax on $\mathrm{CO}_{2}$ emissions as applied to the production of electricity delivered to specific transmission grids in the US $(6,10-11)$. Newcomer, et al (6) studied the short run impact of a price on $\mathrm{CO}_{2}$ on production of electricity in the PJM (a regional transmission organization that coordinates the movement of wholesale electricity in all or parts of Delaware, Illinois, Indiana, 
Kentucky, Maryland, Michigan, New Jersey, North Carolina, Ohio, Pennsylvania, Tennessee, Virginia, West Virginia and the District of Columbia), MISO (Midwest Independent System Operator, which covers all or most of North Dakota, South Dakota, Nebraska, Minnesota, lowa, Wisconsin, Illinois, Indiana, Michigan and parts of Montana, Missouri, Kentucky, and Ohio), and ERCOT (the Electric Reliability Council of Texas) transmission systems and concluded that a tax of \$ 35 per metric ton of $\mathrm{CO}_{2}$ would lead to a $10 \%$ reduction in $\mathrm{CO}_{-2}$ emissions in PJM and MISO, with a $30 \%$ decrease in ERCOT. Most of the reductions identified by Newcomer et al., however, resulted from a lower demand for electricity, rather than from a change in the order of dispatch between gas and coal. A more recent investigation (10) examined the potential impact of a carbon tax on the future ERCOT system focusing specifically on prospects for 2013. Accounting for expected changes in the hourly dispatch of electricity, it was argued, assuming a prevailing price for gas of $\$ 7$ per $\mathrm{MMBTU}$, that a significant reduction in $\mathrm{CO}_{2}$ emissions would require a carbon price of between $\$ 40$ and $\$ 60$ per metric ton of $\mathrm{CO}_{2}$. Cullen (12), using a dynamic econometric model, concluded that a tax of $\$ 20$ per metric ton $\mathrm{CO}_{2}$ would result in only a minimal change in emissions from ERCOT. All these studies were based, however, on specific assumptions with respect to the cost of gas assuming prices (\$7 - \$10 per MMBTU) much higher than values that applied over the period emphasized in the present study. One would not expect under these circumstances significant displacement of coal for gas fired systems: operational expenses for coal systems would remain lower than those for gas ensuring a higher relative position for the former on the economic merit order [Xi: You could include here in the text your definition of economic merit order]. 
Our analysis will be based on an econometric model tuned to data reported for power generation, which covers the time interval $2005-2010$ and will be used specifically to quantify the shift of fuel from coal to gas in response to the changing differential prices for coal and gas. The model will be applied to argue that economically driven coal to gas substitution was primarily responsible for the recent decrease in the use of coal in the power sector and for the corresponding reduction in emissions of $\mathrm{CO}_{2}$.

\section{Data and Methodology}

The mix of systems available for generation of electricity to meet load demand in real time varies significantly across the US. The fraction of electricity generated using gas for example is particularly high in New England. Coal, in contrast, provides the dominant source for power in the Midwest (13). We elected for this reason to apply our analysis of the power sector on a regional rather than national basis, choosing to explore specifically patterns and trends in generation for the nine census regions of the US as depicted in Figure 1. Alaska and Hawaii were excluded from the Pacific census region on the grounds that generation of power using coal is negligible in these states. Capacities for power generation in the different census regions are also indicated in Figure 1.

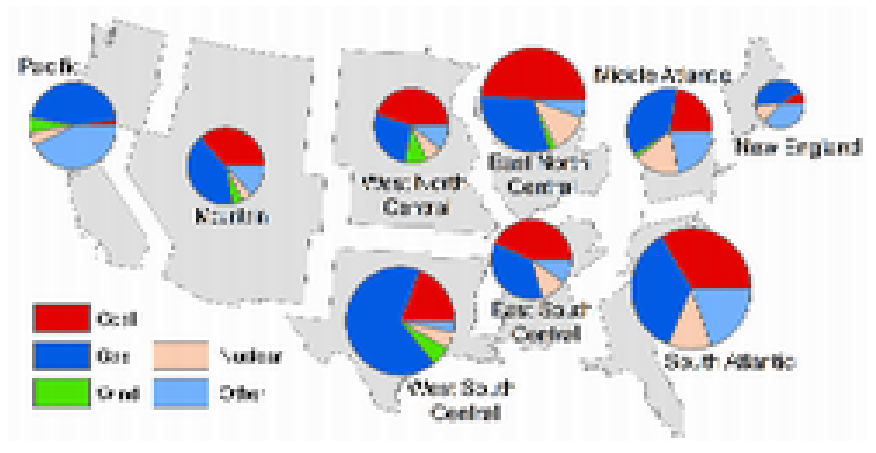


Figure 1 Illustration of the 9 census regions considered in this study together with a breakdown of the fractional capacities available for production of electricity using coal, gas, wind, nuclear and other. The size of elements in the pie charts reflects the relative amount of installed capacities for individual regions. Capacity data included here refer to 2009. (Data source: http:/ Lwww.eia.gov/cneaf/electricity/epa/existing capacity state.xls, read July 2, 2011)

As noted above, it is important that the model be applied on a regional rather than national basis. There is little opportunity to achieve savings in emissions of $\mathrm{CO}_{2}$ for example in the New England region where the generating mix is already heavily weighted to gas and where coal makes only a minor contribution to total power production. The response to a changing price for gas relative to coal depends clearly on the specific mix of generating systems available in a particular region.

The change in the fraction of electricity generated using coal relative to natural gas in any given region depends on the differential costs for production associated with individual power plants (O\&M plus fuel). We shall assume in what follows that the fraction of electricity produced using non-coal, non-gas sources is constant reflecting its higher position on the economic merit order. Modern NGCC plants are capable of converting gas energy to electricity with an efficiency averaging approximately $45 \%$ (as high as $51 \%$ in the best cases). In contrast, the efficiency for coal-fired plants averages $33.6 \%$ on a national basis with some of the oldest plants operating at efficiencies lower than $20 \%(8-9,13)$. With the decrease in prices of natural gas from 2008 to 2009, efficient NGCC gas systems were increasingly able to compete with inefficient coal systems in terms of costs for power generation. Older and less efficient coal units were displaced as a consequence. 
The change in the deployment of generation facilities in response to the change in the differential price for gas relative to coal is clearly indicated in the data for the East South Central region summarized in Figure 2. The results displayed here contrast the frequency with which different plants were deployed to accommodate demand in 2008 when gas prices were relatively high as compared to 2009 when gas prices were comparatively low. Costs for generation of electricity with conventional coal-fired plants in 2008 ranged from about $2.5 \mathrm{c} /$ $\mathrm{kWh}$ to about $3.5 \mathrm{c} / \mathrm{kWh}$ as compared to $6.5 \mathrm{c} / \mathrm{kWh}$ to $8.5 \mathrm{c} / \mathrm{kWh}$ for NGCC. The decrease in gas prices in 2009 combined with a modest increase in the price of coal resulted in a dramatic shift in the mix of generation facilities employed to meet demand. Costs for generation of electricity using NGCC plants decreased by close to $4 \mathrm{c} / \mathrm{kWh}$ in 2009 ensuring competition for coal and NGCC in the economic merit order. When fuel costs for gas are high relative to coal, we might expect the fraction of electricity produced using coal as compared to gas to be relatively constant (determined primarily by the magnitude of the existing coal capacity). In the opposite limit, where fuel costs for gas are more favorable than those for coal, the fraction of power generated using coal should again approach a constant (much lower in this instance). Coal plants would be deployed in this case only under circumstances where the capacity of the gas system is insufficient to meet demand. The results in Figure 2 illustrate the response of the composite generation system to these influences. 


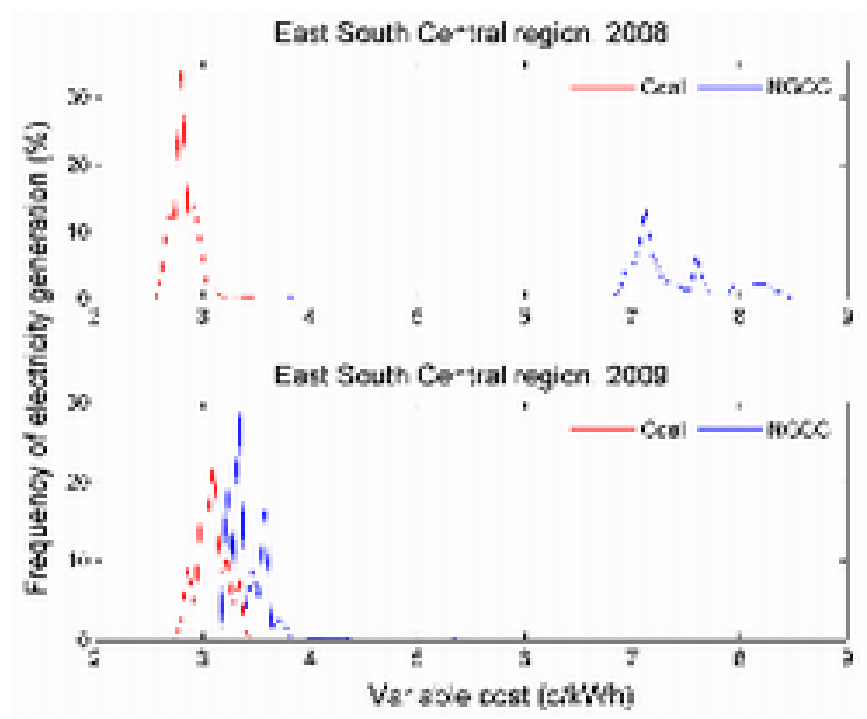

Figure 2 Frequency for generation of electricity using coal and gas systems in the East South Central Region for 2008 and 2009. Data are plotted for every $0.06 \mathrm{c} / \mathrm{kWh}$ change in generation cost. Data were derived from EIA-906, EIA-920, and EIA-923 prepared by US Energy Information Administration (http://www.eia.gov/cneaf/electricity/page/eia906 920.html). Note that the distributions overlap in 2009 in response to the lower prices for gas that prevailed in that year as compared to 2008.

Our interest here is in the transition between these limiting conditions constrained by the existing capacities for electricity generation. In the simplest case we assumed a linear function to describe the behavior of the coal fraction in the transition zone. A second approach adopted a parameterization based on an assumption that the fractions of electricity generated using coal and gas could be described as functions of cost by Gaussian distributions. The transition zone is identified in this case by the convolution of these two functions. In practice we found that the behavior of the coal fraction as a function of the difference in cost for generation using gas rather than coal could be described satisfactorily by a bi-asymptotic function of the form: $a\left(1+e^{c x}\right)^{-1}$, where $\mathrm{x}$ denotes the difference in average costs 
for generation of electricity using gas as compared to coal ( $x$ depends not only on the difference in fuel costs but also on the difference in efficiencies with which fuel energy is converted to electricity). The extent to which generation using coal is replaced by generation using gas should depend also on the capacity of the gas systems available to accommodate this substitution. Incorporating this consideration, we assume that the fraction, $f$, of electricity generated using coal rather than NGCC systems in any particular region may be represented by a function of the form:

$$
f=a\left(1+e^{c x}\right)^{-1}+b y+d
$$

where $y$ denotes the fraction of available capacity represented by NGCC and $a, b, c$, and $d$ are constants to be determined by fitting this relation to actual power data.

In the limit of large $x$ (gas generation costs much higher than coal), $f$ tends to by+d (the parameter $d$ depends implicitly on the available capacity for coal). In the limit for which gas generation costs are much lower than those for coal, $\mathrm{x}$ is large and negative: $f$ tends to $a+b y$ $+d$ in this case (the constant $a$ is negative). The fitting curve would exhibit an inflection point (second derivative equals 0 ) at $x=0$.

The data adopted in the present analysis were derived from the publically accessible data base prepared by U.S. EIA. The monthly fractions of electricity generated using coal in each region were aggregated from data on electricity production reported on a monthly basis by generator type on Forms EIA-906, EIA-920, and EIA-923 (http://www.eia.gov/cneaf/ electricity/page/eia906 920.html) and EIA 423 published by US EIA (http://www.eia.gov/cneaf/ 
electricity/forms/eia923.pdf) . The corresponding data on the capacities of NGCC gas systems were taken from Form EIA-860 (http://www.eia.gov/cneaf/electricity/page/eia860.html). Prices for coal and natural gas were adjusted using inflators based on the Consumer Price Index (CPI) and are quoted in all cases in terms of September 2010 dollars. Fuel prices for natural gas are quoted in units of price per volume (\$ per thousand cubic feet, or $\$ / K c f)$. These data were converted to energy units (\$/MMBTU) using average heat contents (MMBTU/Kcf) reported on an annual basis for natural gas (year to year variations in heat contents are relatively minor). Heating rates used to calculate generation costs were based on mean values for the different classes of plants (coal and NGCC) excluding plants incorporating combined heat and power (CHP) for which it is difficult to isolate the electricity-only component. The data adopted in this analysis are summarized in Table s2 of the Supporting Information (SI).

The parameters $\left({ }^{a}, b, c\right.$ and $d$ ) of the econometric model described in Equation (1) were estimated on the basis of optimal fits to the data presented in Figure 3. The individual data points in Figure 3 reflect detailed results for state-by-state power production reported by US EIA. When the cost differential for generation of electricity using NGCC is high relative to generation using coal (gas prices much higher than coal), the coal system may be expected to operate at an essentially constant level (competition between coal and gas is minimal). In this case, the fitting curve should asymptote to a constant. Accounting for this in the fitting procedure, we constrained the analysis to require that the derivative of the fits as a function of the cost differential $x$ should not exceed $5 \%$ at $x=6$ cents $/ k W h$. Parameters corresponding to the different regional fitting functions are summarized in Table S2 of the SI. 


\section{Results}

Results in Figure 3 summarize data on the fraction of power generated using coal for the nine census regions over the period October 2005 to September 2010. Individual points reflect results for different months. Data are presented as functions of the difference in costs for generation of a kWh of electricity using gas as compared to coal (gas - coal).

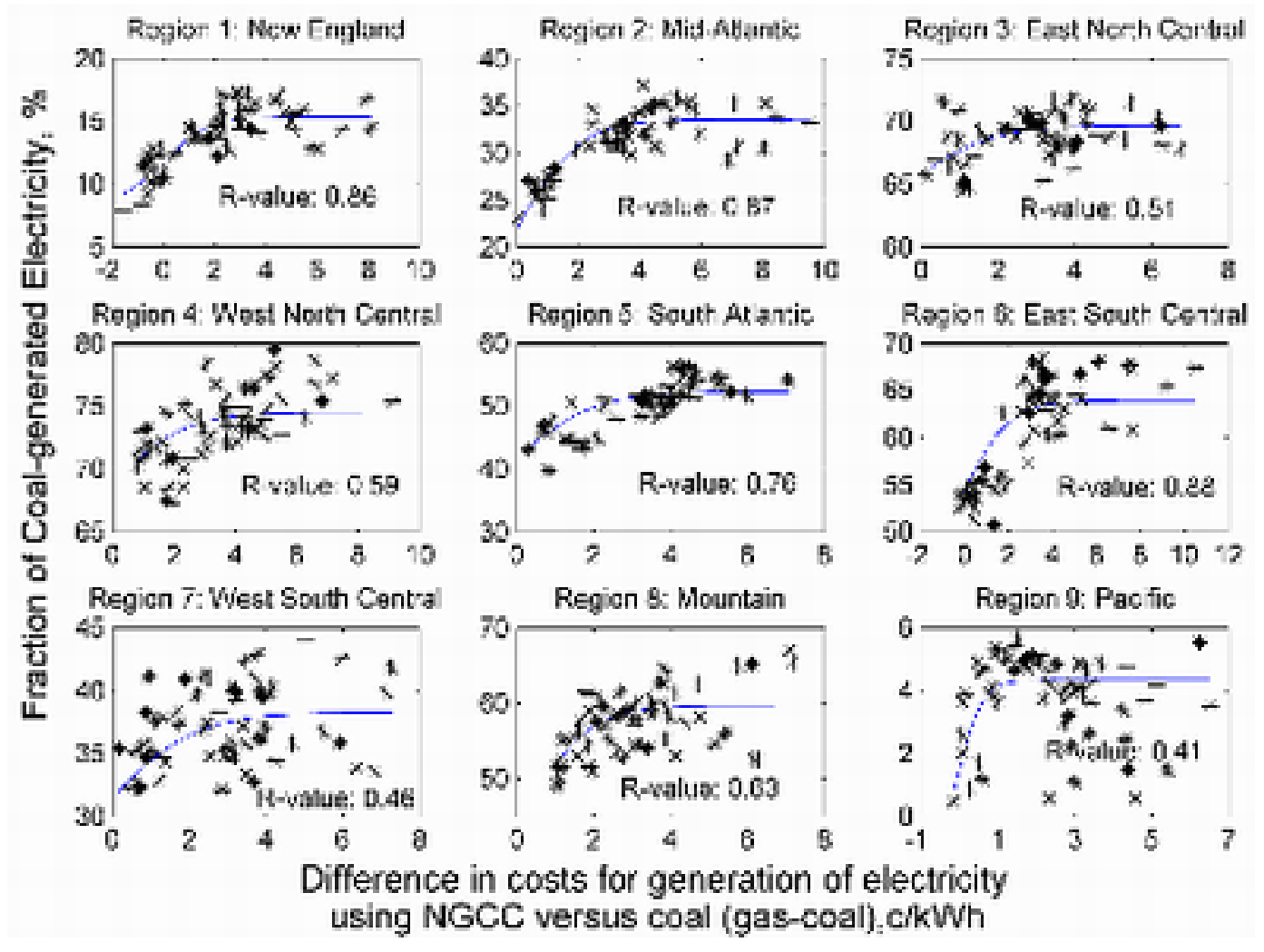

Figure 3 Fraction of electricity generated using coal for each of the 9 census regions displayed in Figure 1. Results are presented as functions of the difference in costs for generation of electricity using NGCC relative to coal (gas-coal). Individual data points reflect reported monthly averages for the different regions. The solid lines indicate fits to the data using equation 1 with R-values as indicated. Parameters corresponding to the fitting functions are presented in the SI. The fits were constrained to require that the derivative of the fits as a function of the cost differential $x$ should not exceed $5 \%$ at $x=6$ cents $/ k W h$. 
Equation 1 provides good to excellent fits to the majority of the data presented in Figure 3. Values for the parameters assumed in this fitting procedure $(a, b, c$ and $d)$ are summarized in SI (Table s1). R-values vary from a high of 0.88 for the East South Central region to a low of 0.41 for the Pacific region. In addition to the East South Central region, the fit is particularly good for the New England, Mid Atlantic, and South Atlantic regions. Results in all cases with the exception of the Pacific region indicate a notable decrease in the use of coal when the gascoal cost differential falls below 2-3 cents/kWh. Gas to coal substitution is greatest in regions for which the capacities of coal and gas are both significant, notably in the Mid Atlantic, South Atlantic, and East South Central regions. Results for the Pacific region exhibit a significant scatter, not surprising in this case since coal is responsible for only a small fraction of the power generated in this region.

Wind accounted for $10 \%$ of the total power generating capacity for the West North Central region, $6.5 \%$ for the West South Central region, $5.2 \%$ for the Mountain region, and 5.8\% for the Pacific region in 2009 (13). Gas systems are typically deployed to compensate for conditions when supplies from wind are relatively low. The intermittent nature of the source from wind, particularly at high levels of wind penetration, results in additional variability in the use of gas, reflected further in the fraction of power generated using coal, accounting for the enhanced scatter of the points for these regions in Figure 3 (11).

The results in Figure 3 can be aggregated to calculate the nationwide response of power generation to the changing differential cost of production from gas relative to coal. As indicated earlier, total U.S. consumption of electricity declined by $4.1 \%$ in 2009 relative to 2008 . 
Production from sources other than coal and NGCC increased by $0.68 \%$. These data imply a decrease of $6.73 \%$ in generation from the combination of coal and NGCC, reflecting a decline of $11.63 \%$ in generation from coal offset by a rise of $7.18 \%$ in production from gas (2). The analysis outlined above indicates a decrease of $11.77 \%$ in the share from coal together with an increase of $7.58 \%$ in production from gas in excellent agreement with the trends observed in practice.

Existing US coal fired power plants are responsible on average for emissions of 0.968 tons of $\mathrm{CO}_{2}$ per $\mathrm{MWh}$ of electricity in contrast to the much lower emission of 0.400 tons per MWh for the existing NGCC system (14-15). On an equal energy basis, consumption of coal is responsible for nearly twice the level of $\mathrm{CO}_{2}$ emissions as compared to emissions associated with consumption of natural gas. The even greater differential in the results quoted here accounts for the higher efficiency with which electricity is produced from NGCC plants relative to plants fueled by coal.

The decrease in power generation between 2008 and 2009, combined with the changing mix of generation using coal and gas resulted in a reduction of $8.76 \%$ over this period in emissions of $\mathrm{CO}_{2}$ from the US power sector. If the relative contributions of power produced from coal and gas had remained constant, the reduction, responding to the decrease in demand, would have been much less, $4.12 \%$. The analysis outlined here suggests that fuel switching driven by the observed decrease in the differential cost for generation using coal versus gas was responsible for a decrease of $4.28 \%$ in emissions over and above what would have occurred as a result of the recession. 
Introduction of a carbon tax on the power sector would have an impact similar to that associated with a decrease in the differential cost for generation of power using gas as compared to coal: generation costs for both fuel sources would rise, but those for coal would rise more due to its greater intensity with respect to emissions per MWh of electricity generation. A price for carbon would prompt further substitution of gas for coal with an additional reduction in emissions of $\mathrm{CO}_{2}$ assuming existing capacities and current demand for electricity. The response projected for three levels of carbon tax $\left(\$ 5 /\right.$ ton $\mathrm{CO}_{2}, \$ 10 /$ ton $\mathrm{CO}_{2}$ and $\$ 20 /$ ton $\left.\mathrm{CO}_{2}\right)$ is evaluated for each of the nine census regions using the econometric model described above, with results summarized in Figure 4. As expected, the carbon tax is most effective at low levels of cost differential for gas versus coal: substitution of gas for coal is greatest under conditions corresponding in the steep portions of the transition zones identified in Figure 4. 


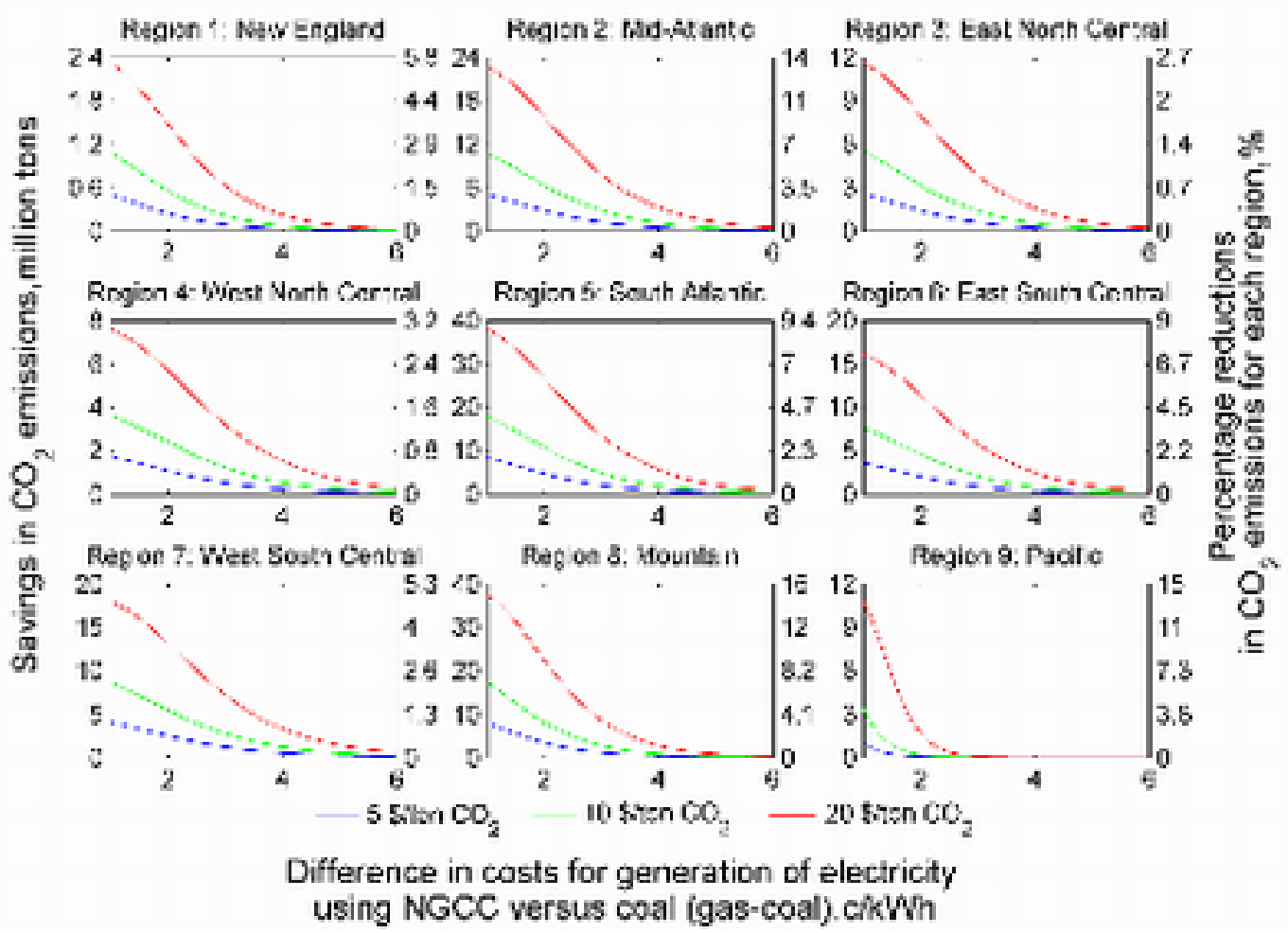

Figure 4 Savings in emissions of $\mathrm{CO}_{2}$ as a function of the difference in costs (cents/kWh) for power generation using NGCC rather than coal (gas-coal) estimated to result from imposition of a carbon tax on the power sector for three levels of $\operatorname{tax}\left(\$ 5 / \operatorname{ton} \mathrm{CO}_{2}, \$ 10 /\right.$ ton $\mathrm{CO}_{2}$ and $\$ 20 /$ ton $\mathrm{CO}_{2}$ ). The vertical axes to the left indicate the magnitude of the $\mathrm{CO}_{2}$ reductions measured in millions of tons $\mathrm{CO}_{2}$. The scales to the right present these data in terms of percentage reductions for each region.

To place these results in context, the immediate impact of a price on carbon of $\$ 5 /$ ton $\mathrm{CO}_{2}$ imposed for example in the South Atlantic region would be to raise prices for generation of power for both coal and gas but with a greater impact on the former. Assuming that coal and gas prices responded directly to this tax, results in Figure 4 would imply an additional reduction in emissions of $5.41 \times 10^{6}$ tons $\mathrm{CO}_{2}$ in the South Atlantic region. In practice, though, we might anticipate that the increase in demand for gas prompted by this carbon tax would result in an increase in the price of gas and thus an increase in the gas-coal price differential. The reduction 
in $\mathrm{CO}_{2}$ emissions would be less in this case. Increasing demand would be expected to result in an increase in the price of gas. The impact of such a demand-driven rise could be offset, however, by a decrease in demand for electricity. This compensating decrease in demand might be expected to result then in a level of $\mathrm{CO}_{2}$ emissions similar to what might have been expected in the absence of the projected gas price response. The potential impact of these feedbacks is not incorporated in the present analysis. Results for individual census regions are summarized in Table 1. 
Table 1 Savings in $\mathrm{CO}_{2}$ emissions (millions of tons $\mathrm{CO}_{2}$ per year) for the power sector in response to assumed carbon tax at levels of $\$ 5 /$ ton $\mathrm{CO}_{2}, \$ 10 /$ ton $\mathrm{CO}_{2}$ and $\$ 20 /$ ton $\mathrm{CO}_{2}$ for 2009 for the nine census regions explored in the paper and for the entire contiguous US.

\begin{tabular}{|c|c|c|c|c|}
\hline \multirow{2}{*}{ Region } & \multirow{2}{*}{ Name } & \multicolumn{3}{|c|}{ Carbon Tax } \\
\hline & & $\$ 5 /$ ton $\mathrm{CO}_{2}$ & $\$ 10 /$ ton $\mathrm{CO}_{2}$ & $\$ 20 /$ ton $\mathrm{CO}_{2}$ \\
\hline 1 & New England & 0.61 & 1.18 & 2.04 \\
\hline 2 & Mid-Atlantic & 4.61 & 9.94 & 21.75 \\
\hline 3 & East North Central & 2.50 & 5.34 & 11.46 \\
\hline 4 & West North Central & 1.41 & 3.05 & 6.82 \\
\hline 5 & South Atlantic & 5.41 & 12.12 & 29.25 \\
\hline 6 & East South Central & 4.19 & 8.44 & 16.19 \\
\hline 7 & West South Central & 4.22 & 8.77 & 18.04 \\
\hline 8 & Mountain & 5.36 & 12.40 & 30.89 \\
\hline 9 & Contiguous Pacific & 2.86 & 6.80 & 11.52 \\
\hline 10 & Contiguous U.S. & 31.17 & 68.03 & 147.97 \\
\hline
\end{tabular}

The regional impacts of the carbon tax, as summarized in Figure 4, may be aggregated to national scale. We assume 2009 fuel prices, constant electricity demand, and constant gas and coal capacities (as assumed above). Under this scenario, a price on carbon of $\$ 5$ per tons of $\mathrm{CO}_{2}$ would result an annual national emissions decrease of $31.17 \times 10^{6}$ tons $\mathrm{CO}_{2}$. A tax of $\$ 5 /$ ton $\mathrm{CO}_{2}$ would correspond to an increase of less than $0.3 \mathrm{c} / \mathrm{kWh}$ in the cost for generation of electricity and could contribute a source of annual revenue to the federal treasury of as much as $\$ 12$ billion. A summary of results corresponding to different levels of carbon tax is presented in Table 1. 


\section{Discussion}

The present study focused on the short-term response of the existing US electric system to changes in the differential prices for natural gas as compared to coal including also an analysis of the impact of a potential tax on emissions of $\mathrm{CO}_{2}$. A more comprehensive study should consider the longer-term response including the economics for investment in new generating capacity, the potential retirement of inefficient existing plants, regulations with respect to potentially tighter controls on emissions of conventional pollutants such as $\mathrm{SO}_{2}$, NOx, Hg and particulates (17-18), and expectations (most likely) for a higher future demand for electricity. The present analysis most likely underestimates the eventual savings in $\mathrm{CO}_{2}$ emissions that could be realized in response either to a continuing pattern in fuel prices favoring gas relative to coal or a carbon tax intended to accomplish a similar objective.

Planning for new generation plants must take into account not only operational costs but also expenses for capital investment. Capital costs for NGCC plants are typically lower than costs for coal plants of similar capacity. A low price for natural gas will tend to flatten the slope of the screening curve for NGCC (green line in Figure S1) resulting in a preference for increased investment in NGCC relative to coal plants in the future $(8,12,19)$. The low gas price case considered in the most recent annual energy outlook (AEO2011) by US Energy Information Administration (US EIA, 20) projects a strong continuing growth for investments in natural gas systems. The combination of low gas prices and requirements for retrofitting existing plants to meet anticipated future emission standards will require, it is argued, retirement over the period 2010 to 2035 of coal-fired plants adding up a cumulative capacity of 72.6 GW. The ElA study 
further projects the addition of $150.8 \mathrm{GW}$ of gas-fired systems over this period accounting for up to $71.9 \%$ of anticipated additional future demand, which they argue will be supplied by a combination of renewables (13.6\% of the total), coal $(6.4 \%)$, distributed systems $(5.1 \%)$ and nuclear (3.0\%). Assuming this scenario, annual emissions of $\mathrm{CO}_{2}$ from the power sector would be reduced by approximately 261 million metric tons $\mathrm{CO}_{2}$ relative to the business as usual (BAU) reference case (equivalent to $12.1 \%$ of emissions from the power sector in 2009).

The AEO2011 report further explored the savings in emissions that could be realized through the introduction of an economy wide carbon tax. Such a tax would be expected to shift US power generation toward natural gas, providing incentives in addition for low carbon sources such as renewables and nuclear and potentially also (at high tax levels) for carbon capture and sequestration (CCS). Imposition of a carbon tax would most likely increase the price of electricity delivered to consumers prompting a decrease in demand resulting in a further reduction in emissions of $\mathrm{CO}_{2}$. The report suggests that a price on $\mathrm{CO}_{2}$ emissions rising from \$25 per ton (2009 dollars) in 2013 to \$77 per ton in 2035 would result in an additional reduction of 1444 million metric tons of $\mathrm{CO}_{2}$ emissions per year from the US power sector in 2035 relative to the $\mathrm{BAU}$ reference case (equivalent to about $27 \%$ of total economy wide emissions of $\mathrm{CO}_{2}$ from the US in 2009) (21-22).

Natural gas is expected to play an increasingly important role in the future generation of electricity in the US reflecting anticipated continuing growth in the source from shale. Shale accounted for $14 \%$ of total US natural gas production in 2009 , increasing by close to a factor of three with respect to production in 2006 (3). The potential supply of gas from shale is 
considered large, comparable or even greater than the contribution from conventional sources. Current analysis suggests that the combination of conventional and unconventional reserves (shale, tight gas and coal bed methane) could accommodate current demand for natural gas in the US for at least 100 years (23), although the recent revision in estimates for the potential supply from the Marcellus shale suggests that this value may be somewhat optimistic. In the reference case of AEO2011 report, overall domestic natural gas production is projected to increase from 22.4 trillion cubic feet (Tcf) in 2009 to 26.3 Tcf in 2035, the increase attributed mainly to continuing development of the source from shale. Shale is projected to contribute up to $47 \%$ percent of total US gas production in 2035 , increasing its fractional contribution by close to a factor of 3 with respect to 2009. Growth in the production of gas from shale is projected to reduce US dependence on imported supplies (16). The reference case of AEO2011 concludes that net imports of natural gas are likely to decline from $11 \%$ of total supply in 2009 to $1 \%$ in 2035.

Howarth et al (24) have suggested that emissions of $\mathrm{CH}_{4}$ associated with the fracking process involved in the production of natural gas from shale, combined with release of $\mathrm{CH}_{4}$ in the gas transportation system, could largely offset the climate related advantages occasioned by the additional sources of low cost gas $\left(\mathrm{CH}_{4}\right.$, the major component of natural gas, is a significantly more effective greenhouse gas than $\left.\mathrm{CO}_{2}\right)$. An earlier study by Lelieveld and Crutzen (25) quantitatively analyzing the indirect effects of methane on climate warming on the basis of available estimates of fossil-fuel-related leaks of methane, suggested that switching from coal and oil to natural gas as an energy source would reduce climate warming. They 
further concluded that considering the global warming potential (GWP) on a time scale of ten years, the fractional natural gas leakage should be less than $4.3-5.7 \%$ to ensure a reduction in climate forcing associated with switching from coal to gas. The advantages of natural gas are even more favorable if the potential climate impact is assessed on time scales much longer than a decade. Jiang et al (26) evaluated the greenhouse gas (GHG) emissions resulting from the use of gas extracted from the Marcellus shale considering the entire life cycle of the gas. They offered a comparison with the average emissions resulting from US natural gas produced in 2008, prior to any significant development of the Marcellus system. Their results suggested that the GHG emissions from shale gas over the entire life cycle including the final combustion process are at most $3 \%$ higher than emissions associated with production and consumption of conventional sources of gas. They argued further, in contrast to Howarth et al (24), that the climate impact of the greenhouse gases emitted in conjunction with exploitation of the Marcellus shale source to produce electricity are significantly lower than those associated with the production of power using coal. They concluded that relatively straightforward measures could be implemented to minimize the potential release of greenhouse gases associated with the extraction of gas from shale (26). A more recent study by Hultman, et al (27) adopting a transparent and consistent approach to comparing the GHG footprints of conventional natural gas, shale gas, and coal, concluded that in terms of electricity generation the GHG impacts of shale gas are $11 \%$ higher than those for conventional gas (higher than the value reported by Jiang et al), but only $56 \%$ of the impact expected for coal. 
The advantage of an increase in the supply of natural gas and an associated decrease in the price of the gas relative to coal is clear: a decrease in emissions of $\mathrm{CO}_{2}$ from the power sector; a decrease in coal use and related emissions of environmentally hazardous pollutants including not only $\mathrm{CO}_{2}$ but also $\mathrm{SO}_{2}$, particulates and mercury; and most likely, an increase in the overall efficiency of the national power sector occasioned by more effective utilization of the existing and potential future gas components of the national power system.

\section{Acknowledgement}

We thank Dale Jorgenson, Henry Lee, Chris Nielsen, and Frank O'Sullivan for valuable discussions. This research was supported by the National Science Foundation, grant AGS1019134.

\section{Description of SI}

Values for the parameters $\left({ }^{a}, b, c\right.$ and $\left.d\right)$ of the econometric model estimated on the basis of optimal fits to the data are summarized in Table s1. The data adopted in this analysis are summarized in Table s2. The screening curves for a power system consisting of coal fired system (CFS), gas combined cycle (GCC) and gas combustion turbines (GCT) are presented in Figure s1. A comparison of historical prices of coal and natural gas delivered to the US power sector (expressed dollars in 2010) were illustrated in Figure s2. 


\section{References}

1. US-EPA Inventory of U.S. Greenhouse Gas Emissions and Sinks: 1990-2009; EPA 430R-11-005; U.S. Environmental Protection Agency: Washington, DC, Feburary 15, 2011, 2011; p 444.

2. US-EIA (2010f) Annual Energy Review 2009. in Annual Energy Review, ed US-EIA (U.S. Energy Information Administration, Washington, DC), p 446.

3. US-EIA Natural Gas Monthly; U.S. Energy Information Administration: Washington, DC, December 2010, 2010; p 108.

4. US-EIA Natural Gas Monthly July 2011; DOE/EIA-0130(2011/07); US Energy Information Administration: Washington, DC, 2011; p 107.

5. US-EIA Net Generation by Energy Source: Total. http://www.eia.gov/cneaf/electricity/ epm/table1_1.html (August 2),

6. Newcomer, A.; Blumsack, S. A.; Apt, J.; Lave, L. B.; Morgan, M. G., Short run effects of a price on carbon dioxide emissions from US electric generators. Environmental Science \& Technology 2008, 42, (9), 3139-3144.

7. Meier, A. v., Electric Power Systems: A Conceptual Introduction. IEEE Press : WileyInterscience: Hoboken, N.J., 2006; p 298.

8. Masters, G. M., Renewable and Efficient Electric Power Systems. A John Wiley \& Sons, Inc.: Hoboken, New Jersey, 2004.

9. Platt, K. The Implications of Lower Natural Gas Prices for the Electric Generation Mix in the Southeast; U.S. Energy Information Administration: Washington, DC, May 2009, 2009; p 15.

10. ERCOT Analysis of Potential Impacts of $\mathrm{CO}_{2}$ Emissions Limits on Electric Power Costs in the ERCOT Region; Electric Reliability Council of Texas: Austin, TX, May 12, 2009, 2009; p 35.

11. Cullen, J., Measuring the Environmental Benefits of Wind-Generated Electricity. In 2010; p 61.

12. Cullen, J. A., Dynamic Response to Environmental Regulation in the Electricity Industry. In Industrial Organization Seminar, New Heaven, 2009; p 50 (http://www.econ.yale.edu/ seminars/apmicro/am09/cullen-090924.pdf, read July 15, 2011).

13. US-EIA Electric Power Annual 2009; DOE/EIA-0348(2009); U.S. Energy Information Administration: April 2011, 2011; p 108.

14. US-EPA Emissions of Greenhouse Gases in the United States 2008; DOE/EIA-0573(2008); U.S. Environmental Protection Agency: Washington, DC, Feburary 15, 2011, 2011; p 444.

15. US-EIA Emissions of Greenhouse Gases in the U. S.; DOE/EIA-0573(2009); U.S. Energy Information Administration: Washington, DC, 2011; $\mathrm{p} 86$.

16. Nordhaus, W., A Question of Balance: Weighing the Options on Global Warming Policies. Yale University Press: New Haven, CT, 2008; p 248. 
17. US-EPA, Primary National Ambient Air Quality Standard for Sulfur Dioxide; Final Rule. In 40 CFR Parts 50, 53, and 58, Federal Register: Washington, DC 2010; Vol. EPA-HQ-OAR2007-0352; 9160-4, pp 33519-35603.

18. US-EPA The Cross-State Air Pollution Rule: Reducing the Interstate Transport of Fine Particulate Matter and Ozone; U.S. Environmental Protection Agency: Washington, DC, $2011 ; \mathrm{p} 33$.

19. Lu, X.; McElroy, M. B.; Sluzas, N. A., Costs for Integrating Wind into the Future ERCOT System with Related Costs for Savings in $\mathrm{CO}_{2}$ Emissions. Environ. Sci. Technol. 2011, 45, (7), 3160-3166.

20. US-EIA Annual Energy Outlook 2010 With Projections to 2035; DOE/EIA-0383(2010); U.S. Department of Energy: Washington, DC, 2010a; pp 1-83.

21. US-EIA Annual Energy Outlook 2011 with Projections to 2035; DOE/EIA-0383(2011); U.S. Energy Information Administration: Washington, DC, 2011; p 246.

22. Boden, T.; Marland, G., Global CO2 Emissions from Fossil-Fuel Burning, Cement Manufacture, and Gas Flaring. In 1751-2007 June 8, 2010 ed.; Carbon Dioxide Information Analysis Center (CDIAC): 2010; $p 1$.

23. Moniz, E. t. J.; Jacoby, H. D.; Meggs, A. J. M.; trong, R. C. A.; Cohn, D. R.; Deutch, J. M.; Kaufman, G. M.; Participants, S.; Kenderdine, M. A.; O’Sullivan, F.; v, S. P.; Parsons, J. E.; rez-Arriaga, I. P.; Webster, M. D. The Future of Natural Gas; 978-0-9828008-0-5; Massachusetts Institute of Technology: Cambirdge, MA, 2010; p 104.

24. Howarth, R. W.; Santoro, R.; Ingraffea, A., Methane and the greenhouse-gas footprint of natural gas from shale formations. Clim. Change 2011, 106, (4), 679-690.

25. Lelieveld, J.; Crutzen, P. J., Indirect Chemical Effects of Methane on Climate Warming. Nature 1992, 355, (6358), 339-342.

26. Jiang M, et al. (2011) Life cycle greenhouse gas emissions of Marcellus shale gas. Environmental Research Letters 6(3):9.

27. Hultman, N.; Rebois, D.; Scholten, M.; Ramig, C., The greenhouse impact of unconventional gas for electricity generation. Environ. Res. Lett. 2011, 6, (044008), 9. 